\title{
ANÁLISE DA RETÓRICA JORNALÍSTICA EM NOTÍCIAS DE POPULARIZAÇÃO CIENTÍFICA*
}

\author{
ANALYSIS OF THE JOURNALISTIC RHETORIC IN SCIENTIFIC POPULARIZATION NEWS \\ Cristina dos Santos Lovato** \\ Universidade Federal de Santa Maria - UFSM, Santa Maria, BR
}

\begin{abstract}
RESUMO: Neste trabalho, analisamos a retórica jornalística em 30 notícias de popularização científica, publicadas nos sites das revistas especializadas em jornalismo científico: Ciência Hoje, Galileu e Scientific America Brasil, a fim de verificar como os sentidos de objetividade e de imparcialidade são construídos discursivamente nesses textos. Utilizamos como aparato teórico o Sistema de Avaliatividade proposto por Martin e White (2005), enfatizando o Subsistema de Engajamento. Os resultados indicam a predominância da expansão dialógica por meio de modalizações e de citações e relatos. No entanto, a exclusividade da voz do cientista que realizou a pesquisa popularizada, como a única fonte de avaliação dos fenômenos científicos reportados, anula a objetividade e a imparcialidade nesses textos. Observamos, portanto, uma contradição em relação ao papel da popularização da ciência na sociedade. Nas notícias analisadas, o jornalista assume o papel de mero informante (MOTTA-ROTH; LOVATO, 2011), restringido o processo de popularização da ciência a uma tradução e simplificação das descobertas científicas (HILGARTNER, 1990).

PALAVRAS-CHAVE: retórica jornalística; avaliação na linguagem; notícias de popularização científica.
\end{abstract}

\begin{abstract}
In this work, journalistic rhetoric is analyzed in 30 science news for the general public, published on sites of magazines specialized in scientific journalism - Ciência Hoje, Galileu and Scientific America Brazil - in order to verify how the senses of objectivity and impartiality are constructed discursively in these texts. We use as theoretical apparatus the Appraisal System proposed by Martin and White (2005), emphasizing the Engagement Subsystem. The results indicate the predominance of the dialogic expansion through modalizations and quotes and reports. However, the exclusivity of the voice of the scientist who conducted the research spread for non-specialized audiences, as the only source for the evaluation of the scientific phenomena reported, overturns the objectivity and the impartiality in these texts. We observed, therefore, a contradiction concerning the role of the science popularization in society. In the news analyzed, the journalist assumes the role of mere informant (MOTTAROTH; LOVATO, 2011), restricting the process of science popularization to a translation and oversimplification of the scientific discoveries (HILGARTNER, 1990).

KEYWORDS: journalistic rhetoric; appraisal in language; scientific popularization news.
\end{abstract}

\section{NOTA INTRODUTÓRIA}

As mídias têm como propósito dar conta de acontecimentos que se situam em uma co-temporalidade enunciativa. Segundo Charaudeau (2009, p. 132), independente do meio, buscam aproximar dois momentos da cadeia temporal o instante do surgimento - momento da produção - e o instante da produção midiática consumo da informação -. A notícia é um dos gêneros do âmbito jornalístico que se articula de modo mais intenso sobre esses dois eixos temporais devido a sua natureza factual. "A atualidade é, pois, o que responde à pergunta: o que passa nesse momento? É o que dá a notícia seu caráter factual desprovido, em seu princípio, de qualquer qualificação subjetiva e de qualquer tentativa de explicação de sua razão de ser (CHARAUDEAU, 2009, p. 132)".

É nessa exposição sobre a natureza contemporânea do relato de um fato noticioso, que emergem duas características do gênero notícia amplamente difundidas na literatura da área e que norteiam a retórica do discurso jornalístico: a objetividade e a imparcialidade. Tanto a imparcialidade quanto a objetividade buscam oferecer ao leitor a ciência dos fatos tais como são, deixando a critério do leitor a valoração sobre eles (MIGUEL, BIROLI, 2010). Miguel e Biroli (2010, p. 59) apontam que a imparcialidade e a objetividade estão relacionadas ao pretenso objetivo do discurso jornalístico de expor o mundo tal como ele é e constituem a base central de "esquemas práticos de atribuição de valor ao seu trabalho, na defesa de seu

\footnotetext{
* Este trabalho é parte de um projeto guarda-chuva intitulado "Análise crítica de gêneros com foco em artigos de popularização da ciência" (Bolsa PQ/CNPq no 301962/2007-3), elaborado e coordenado pela professora Dr. Désirée Motta-Roth, no Laboratório de Pesquisa e Ensino de Leitura e Redação (LABLER), da Universidade Federal de Santa Maria, no qual a autora, bolsista CAPES, vem trabalhando como pesquisadora em formação

** cristina.lovato@yahoo.com.br.
} 
trabalho diante das pressões internas e externas ao campo jornalístico e na construção de um referencial ético compartilhado pelos próprios jornalistas (MIGUEL; BIROLI, 2010, p. 59)”.

Nessa perspectiva, analisamos como os sentidos de objetividade e de imparcialidade são construídos discursivamente em notícias de popularização científica (doravante notícias de PC) sobre tópicos de saúde por meio da análise dos elementos linguísticos que compõem o Subsistema de Engajamento. Esse subsistema oferece um quadro teórico para a análise (caracterização) da tomada de posição do enunciador em relação às suas proposições e às proposições de outras vozes inseridas no discurso (MARTIN; WHITE, 2005, p. 92).

As 30 notícias que compõem o corpus do presente estudo são escritas por jornalistas e veiculadas nos sites das revistas especializadas em jornalismo científico: Ciência Hoje, Galileu e Scientific America Brasil. Nas próximas seções, apresentamos o campo de investigação, conceituando a popularização da ciência e o gênero notícia de PC. Na sequência, procedemos à exposição do Sistema de Avaliatividade, enfatizando o Subsistema de Engajamento, aos procedimentos metodológicos empregados para a realização do estudo e à discussão dos resultados obtidos.

\section{FUNDAMENTAÇÃO TEÓRICA}

\subsection{Popularização da ciência: delimitando o campo de investigação}

Uma das questões que surge com frequência em discussões sobre a popularização da ciência é a validade ou não de divulgar os resultados de pesquisas em Ciência e Tecnologia (C\&T) para a sociedade mais ampla (OLIVEIRA, 2007, p. 11). Desse modo, a popularização da ciência passou a ser tema de debate nas várias áreas de conhecimento, que buscam entender o modo de construção e de organização das relações sociais entre indivíduos, grupos e instituições (MOTTA-ROTH; LOVATO, 2011, p. 251). É definida como o processo de reformulação do discurso científico para os meios de comunicação de massa, visando a uma audiência não especializada (CALSAMIGLIA; LOPES FERRERO, 2003, p. 68).

O objetivo do processo de popularização da ciência é, desse modo, inscrever a ciência na agenda de debates da sociedade (GERMANO, 2005; GERMANO; KULESZA, 2007).

[O] acesso às informações sobre $\mathrm{C} \& \mathrm{~T}$ é fundamental para o exercício pleno da cidadania e, portanto, para o estabelecimento de uma democracia participativa, na qual grande parte da população tenha condições de influir, com conhecimento em decisões e ações políticas ligadas a C\&T. (OLIVEIRA, 2007, p. 13)

Motta-Roth (2009, p.138) destaca que a sociologia da ciência tem se dedicado a investigação da produção de conhecimento como um processo dialógico, "em que a ciência e sua popularização são importantes e se retroalimentam”. Assim, a popularização passa a influenciar e a estimular a produção de conhecimento, possibilitando "a aprendizagem do cientista sobre as pesquisas em outras áreas, a comunicação entre os próprios cientistas e entre os cientistas e a sociedade (2009, p. 138)".

O gênero notícia de PC pode ser considerado, portanto, uma das várias possibilidades que permite ao público não especializado um mínimo de controle sobre as atividades realizadas nas universidades e laboratórios, combatendo "a visão da ciência como algo muito além do conhecimento do cidadão comum e próxima de uma visão dogmática da verdade” (GERMANO, 2005, p. 04). Esse gênero é definido por Motta-Roth e Lovato (2011, p. 257-258) como

um texto publicado pela mídia autodefinida de PC, que relata e comenta resultados de pesquisas científicas recentes de modo a explicar seu conteúdo e sua relevância para a audiência-alvo da publicação. Muito frequentemente uma notícia de PC tem três partes: (i) uma síntese (o título, que tenta captar o interesse do leitor, a linha de apoio com uma síntese dos resultados da pesquisa, o lide do primeiro parágrafo, com as principais informações sobre quem, onde e quando relativos ao estudo); (ii) um detalhamento (a metodologia adotada, o avanço feito em relação ao conhecimento estabelecido e explanação dos resultados) e (iii) uma conclusão avaliativa (sobre a relevância da pesquisa para a audiência-alvo da mídia, suas consequências e o significado para a sociedade, seu valor para a área, as lacunas e as expectativas remanescentes) (Motta-Roth e Marcuzzo, 2010, p. 518). Nessa última porção da notícia, concentram-se as reações verbais de atores sociais à pesquisa, seus resultados e implicações. 
O propósito comunicativo desse gênero é expandir o conhecimento científico para o público não especializado, recontextualizando e reformulando esse conhecimento (MOTTA-ROTH; LOVATO, 2009, p. 238).

Na próxima seção, fazemos uma revisão das bases epistemológicas e princípios norteadores do Sistema de Avaliatividade proposto por Martin e White (2006) e dos subsistemas que o constituem, destacando o Subsistema Engajamento.

\subsection{Sistema de Avaliatividade: bases epistemológicas e conceitos fundamentais}

O livro The Language of evaluation: appraisal in English, escrito por Martin e White (2005), oferece um inventário de recursos linguísticos para a análise da avaliação na linguagem. Segundo Cabral e Barros (2006, p. 725), o propósito principal dos autores é oferecer um aparato teórico que possibilite explorar o modo como a linguagem é utilizada para avaliar, adotar posicionamento, julgar atos e eventos/coisas concretas por meio do elogio e da censura.

Fundamentada pelos preceitos teóricos formulados por Halliday na Gramática Sistêmico-Funcional, a abordagem diz respeito ao modo como os recursos interpessoais da linguagem (verbos modais, por exemplo) funcionam e se articulam para o estabelecimento das relações intersubjetivas entre os participantes do discurso, enfatizando o posicionamento da voz autoral em relação ao seu enunciado e ao enunciado de outras pessoas e buscando compreender como se dá a construção de envolvimento, de distância, de identidade e de autoridade no discurso. A Figura 1 ilustra o Sistema de Avaliatividade.

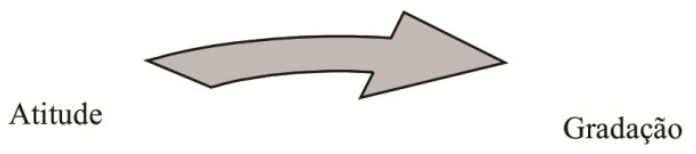

Sistema de Avaliatividade

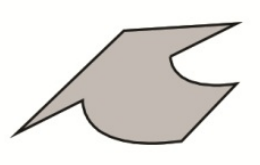

Engajamento

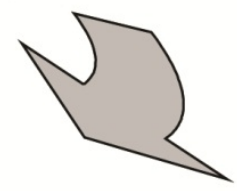

Figura 1 - Sistema de Avaliatividade (MOTTA-ROTH, LOVATO, 2011, p. 255).

O Sistema de Avaliatividade é composto por três subsistemas: Atitude, Gradação e Engajamento. O Subsistema de Atitude abarca os sentimentos positivos ou negativos do falante, em termos de reações emocionais, julgamentos de comportamento e avaliação estética de pessoas e de coisas (MARTIN; WHITE, 2005, p. 35). Divide-se em afeto, incluindo reações emocionais perante situações/coisas/pessoas; julgamento, compreendendo a avaliação sobre o comportamento de pessoas e instituições (em termos de capacidade, normalidade, tenacidade, veracidade e propriedade) e apreciação, englobando as avaliações de caráter estético acerca de coisas, eventos e seres vivos. O Subsistema de Gradação diz respeito à maneira como os falantes/escritores alteram a força e o foco de suas avaliações e pode ocorrer tanto para maximizar, quanto para minimizar uma reação emocional e/ou um julgamento. Por fim, o Subsistema de Engajamento diz respeito ao modo como a voz autoral se posiciona em relação ao seu enunciado a ao enunciado de vozes externas ao texto, conforme será explicado na seção que segue.

\subsubsection{Subsistema de Engajamento: princípios básicos}

O Subsistema de Engajamento está fundamentado nas noções de dialogismo e de heteroglossia propostas por Bakhtin, visto que buscam descrever o modo como os falantes/escritores reconhecem discursos anteriores aos seus e de que maneira se engajam ou não com esses discursos. Segundo Martin e White (2005, p. 95), o Sistema de Engajamento serve para observar como é realizada, linguisticamente, a negociação de significado entre enunciador e enunciatário, em termos de alinhamento e desalinhamento, de acordo com as posições referenciadas no/pelo texto e como essa negociação interfere na relação que o texto constrói entre enunciador e enunciatário. 
Nessa perspectiva, a questão central diz respeito ao modo como o enunciador mobiliza recursos linguísticos, que indicam um determinado ponto de vista, partindo do pressuposto de que o enunciatário compartilha (ou não) esse ponto de vista com ele. Alinhamento e desalinhamento são, portanto, termos-chave nesse subsistema e estão relacionados à noção de solidariedade, que passa a significar a capacidade do tex to de tolerar pontos de vista alternativos (MARTIN; WHITE, 2005, p. 95).

O Subsistema de Engajamento é dividido em duas categorias gerais: expansão dialógica e contração dialógica. $\mathrm{Na}$ expansão dialógica, o falante/escritor apresenta o tópico desenvolvido como uma questão em aberto, produzindo um efeito de convite a alternativas ou posicionamentos dialógicos contrários. Ocorre por acolhimento e por atribuição. O acolhimento engloba significados que o falante/escritor alcança por meio de declarações de probabilidade, sinalizadas léxico-gramaticalmente pelos verbos modais (parece, poderia, deveria), adjuntos modais (talvez, provavelmente); atributos modais (é possível que, é provável que); circunstâncias (em minha opinião) e via certos processos mentais (eu suspeito que, eu acho que, eu acredito que, estou convencido que) (MARTIN; WHITE, 2005, p. 104-105). A atribuição compreende formulações que separam a voz autoral da declaração exposta, atribuindo-a a uma voz não autoral por meio do relato e citações. Ocorre por reconhecimento ou por distanciamento. A atribuição por reconhecimento inclui significados expressos por processos verbais neutros, empregados para reportar as palavras de outras pessoas, tais como os processos verbais dizer, relatar, declarar e circunstâncias de ângulo como de acordo com e segundo $X$ (MARTIN; WHITE, 2005, p.112). A atribuição por distanciamento produz uma separação explícita da voz autoral em relação às declarações das vozes não autorais inseridas no texto. É sinalizada pelo emprego de citações e de proposições projetas pelos verbos defender e alegar (MARTIN; WHITE, 2005, p. 113).

A contração dialógica compreende os sentidos que restringem o espaço dialógico à prevalência de um ponto de vista. É dividida em refutação e em declaração (MARTIN; WHITE, 2005, p. 117). A refutação ocorre por negação ou por contestação. A negação é utilizada para introduzir uma posição alternativa positiva, engajar-se com ela, para rejeitá-la na sequência. É sinalizada pelos advérbios de negação não, nem, nunca e jamais, por exemplo (MARTIN; WHITE, 2005, p. 118). A contestação engloba as proposições que substituem ou suplantam outras, é realizada léxico-gramaticalmente pelas conjunções embora e mas, por exemplo (MARTIN; WHITE, 2005, p. 120). Por fim, a declaração envolve a ênfase autoral explícita (Eu afirmo..., Os fatos em questão são..., A verdade é que..., por exemplo). Ocorre por concordância (com certeza, naturalmente, certamente), endosso (voz não autoral correta, válida e confiável - mostra, demonstra e comprova, confirma) e pronunciamento (intervenção autoral explícita - Eu defendo..., Os fatos em questão são..., Podemos concluir que...) (MARTIN; WHITE, 2005, p. 121-122). A Figura 2 resume o Subsistema de Engajamento.

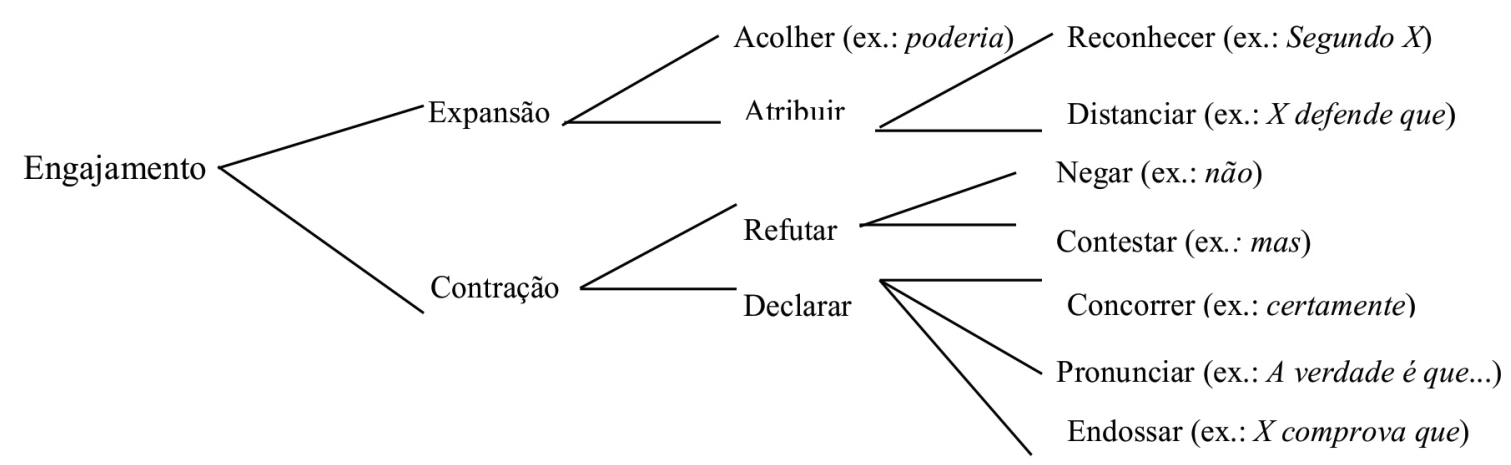

Figura 2. Subsistema de Engajamento, com base em Martin e White (2005).

Na sequência, são detalhados os procedimentos metodológicos empregados para a realização deste estudo.

\section{METODOLOGIA}

O presente trabalho é de cunho qualiquantitativo. O corpus de análise é composto por 30 notícias de PC sobre tópicos relacionados à saúde, extraídas das versões online das revistas Ciência Hoje (CH), Galileu (GL) e Scientific America Brasil (SCIAMB) (Quadro 1). 


\begin{tabular}{|c|c|c|}
\hline $\mathrm{CH}$ & GL & SCIAMB \\
\hline \#1 Ameaça invisível & $\begin{array}{l}\text { \#1Camiseta suja de mulher deixa } \\
\text { homem excitado }\end{array}$ & $\begin{array}{l}\text { \#1 Novos instrumentos permitem biópsias } \\
\text { virtuais para detecção do câncer }\end{array}$ \\
\hline \#2 Boa forma física e intelectual & $\begin{array}{l}\text { \#2 Chefe incompetente é mais } \\
\text { agressivo, indicam estudos }\end{array}$ & $\begin{array}{l}\text { \#2 Profissionais não especializados viabilizam } \\
\text { tratamento eficaz da ansiedade }\end{array}$ \\
\hline $\begin{array}{l}\text { \#3 Esperança contra o câncer em } \\
\text { óleos vegetais }\end{array}$ & $\begin{array}{l}\text { \#3 Cientistas estudam como vermes } \\
\text { podem inibir alergias }\end{array}$ & $\begin{array}{l}\text { \#3 Contato com fumaça de cigarro afeta saúde } \\
\text { de fetos }\end{array}$ \\
\hline \#4 Guerra Microbiana & $\begin{array}{l}\text { \#4 Genes 'melhores' podem fazer } \\
\text { mulher ter mais parceiros }\end{array}$ & $\begin{array}{l}\text { \#4 Coração pode revelar informações sobre a } \\
\text { saúde dos rins }\end{array}$ \\
\hline \#5 O usuário padrão de maconha & $\begin{array}{l}\text { \#5 Hormônio ajuda menino a gostar } \\
\text { mais de bola }\end{array}$ & $\begin{array}{l}\text { \#5 Criado mosquito imune ao parasita da } \\
\text { malária }\end{array}$ \\
\hline \#6 Poeira tóxica & \#6 Maconha pode 'desativar' esperma & $\begin{array}{l}\text { \#6 Deficiência de vitamina D está ligada a } \\
\text { mutações genéticas }\end{array}$ \\
\hline \#7 Quer perder peso? Suba a serra! & $\begin{array}{l}\text { \#7Obesidade pode proteger contra } \\
\text { problemas do coração, diz estudo }\end{array}$ & $\begin{array}{l}\text { \#7 Desenvolvido novo medicamento para o } \\
\text { tratamento de endometriose }\end{array}$ \\
\hline $\begin{array}{l}\text { \#8 Caramujo pode disseminar } \\
\text { doenças }\end{array}$ & $\begin{array}{l}\text { \#8 Pílula pode reduzir danos aos } \\
\text { pulmões de quem fuma }\end{array}$ & $\begin{array}{l}\text { \#8 Contaminação microbiana cruzada é } \\
\text { problema oculto em cozinhas comerciais }\end{array}$ \\
\hline $\begin{array}{cc}\text { \#9 } & \text { MAIS EXERCÍCIO PARA } \\
& \text { MANTER A BOA FORMA }\end{array}$ & $\begin{array}{l}\text { \#9 Restos do cigarro também fazem } \\
\text { mal, afirma estudo }\end{array}$ & $\begin{array}{l}\text { \#9 Arroz branco aumenta risco de diabetes } \\
\text { tipo } 2\end{array}$ \\
\hline \#10 FIM DA PICADA & $\begin{array}{l}\text { \#10 Alguns protetores solares podem } \\
\text { acelerar o câncer, diz estudo }\end{array}$ & $\begin{array}{l}\text { \#10 Como foi sua última refeição? Se comeu } \\
\text { fora, correu riscos }\end{array}$ \\
\hline
\end{tabular}

\section{Quadro 1 - Notícias do corpus.}

Cada notícia foi rotulada com um código composto pelas iniciais da revista de onde foram extraídas e enumeradas de um a dez. A notícia intitulada Ameaça Invisível, publicada pela $\mathrm{CH}$, é referenciada na discussão dos resultados por $\mathrm{CH \# 1,} \mathrm{por} \mathrm{exemplo.}$

\subsection{Procedimentos de análise}

O texto das notícias foi parcelado em blocos, na sequência, procedemos à marcação e à classificação manual das ocorrências do Subsistema de Engajamento. A partir dessa marcação, foi realizado um mapeamento quantitativo das ocorrências desse subsistema e uma análise qualitativa, a fim de relacionar os dados obtidos com o modo de funcionamento do gênero em questão, em termos de tentativa de construção de um discurso imparcial e objetivo. Para fins de análise, optamos por analisar somente o posicionamento do jornalista em relação as suas proposições e às proposições das vozes não autorais inseridas nas notícias.

Nesse trabalho, exemplificamos e discutimos somente as categorias mais recorrentes. Na próxima seção, os dados obtidos e triangulados nesses procedimentos são discutidos, primeiramente por meio da exposição dos percentuais obtidos e, na sequência, através de exemplos extraídos do corpus de análise.

\section{RESULTADOS E DISCUSSÃO}

Os dados levantados indicam que a expansão dialógica é predominante nas notícias de PC analisadas, conforme demonstram as Tabelas 1, 2 e 3. A Tabela 1 ilustra a percentagem de ocorrência do Subsistema de Engajamento nas notícias da $\mathrm{CH}$.

Tabela 1 - Mapeamento do Subsistema de Engajamento nas notícias da Ciência Hoje:

\begin{tabular}{|c|c|c|c|c|c|c|c|c|c|}
\hline \multirow{3}{*}{$\begin{array}{c}\text { Ciência } \\
\text { Hoje }\end{array}$} & \multicolumn{3}{|c|}{ Expansão dialógica } & \multicolumn{5}{|c|}{ Contração dialógica } & \multirow{3}{*}{ Total } \\
\hline & \multirow[t]{2}{*}{ Acolher } & \multicolumn{2}{|c|}{ Atribuir } & \multicolumn{2}{|c|}{ Refutar } & \multicolumn{3}{|c|}{ Declarar } & \\
\hline & & Reconhecer & Distanciar & Negar & Contestar & Concorrer & Pronunciar & Endossar & \\
\hline $\begin{array}{c}\text { Total } \\
\text { parcial }\end{array}$ & 25 & 71 & 06 & 08 & 12 & 02 & $\mathbf{0}$ & 25 & \\
\hline$\%$ & $24 \%$ & $69 \%$ & $5 \%$ & $17 \%$ & $25 \%$ & $4.2 \%$ & $\mathbf{0}$ & $53 \%$ & 149 \\
\hline $\begin{array}{c}\text { Total } \\
\text { absoluto }\end{array}$ & \multicolumn{3}{|c|}{102} & \multicolumn{5}{|c|}{47} & \\
\hline$\%$ & \multicolumn{3}{|c|}{$68 \%$} & \multicolumn{5}{|c|}{$31 \%$} & \\
\hline
\end{tabular}


A Tabela 1 mostra que, nas notícias da $\mathrm{CH}$, os sentidos da expansão dialógica ocorrem frequentemente por meio do acolhimento e da atribuição por reconhecimento. Os exemplos 1 e 2 ilustram a ocorrência do acolhimento e da atribuição por reconhecimento (itálico).

Exemplo 1

CH\#6 Pesquisa do Ipen identifica metais pesados e aditivos usados na fabricação de plásticos no pó acumulado em residências de São Paulo. Os compostos podem causar diversos problemas à saúde, como anemia, alergias, distúrbios endócrinos e até mutações genéticas.

CH\#8 O caramujo-gigante-africano infectado por Angiostrongylus pode contribuir para a disseminação de duas doenças causadas por esse verme: a angiostrongilíase abdominal e a meningoencefalite eosinofílica

No exemplo 1, a utilização de modais de probabilidade pode causar (CH\#6) e pode contribuir (CH\#8) possibilita ao jornalista diminuir o grau de assertividade dos enunciados, indicando que podem existir posicionamentos alternativos contrários àqueles apresentados na notícia PC.

Exemplo 2

CH\#2 Segundo I-Min Lee, professor da Escola de Medicina Harvard e coautor do estudo, o processo metabólico é muito mais complexo quando o objetivo é emagrecer, já que o organismo precisa gastar muito mais calorias.

CH\#5 Um de seus autores, Paulo Menezes explica que a prioridade inicial era avaliar o consumo de álcool. Mas as respostas relacionadas à maconha surpreenderam os pesquisadores.

A atribuição por reconhecimento manifesta de modo explícito a recorrência a uma voz externa por meio de circunstâncias de ângulo (Segundo I-Min Lee - CH\#2 -) e processos verbais (explicam-CH\#5-). A natureza neutra das circunstâncias de ângulo e dos processos verbais utilizadas para introduzir a proposição dificulta a identificação da distância retórica estabelecida pelo jornalista em relação ao conteúdo das proposições projetadas.

Entretanto, se o emprego de verbos modais e citações e relatos indica que, no nível da léxico-gramática, a opinião do jornalista é mascarada; por outro, a presença exclusiva da voz do pesquisador que realizou a pesquisa, como fonte oficial das informações, indica que o jornalista restringe o espaço dialógico à opinião do pesquisador, alinhando-se com seu ponto de vista ao trazê-lo para o texto como a fonte oficial das informações noticiadas (MOTTA-ROTH, LOVATO, 2011, p. 263). Essa característica das notícias da CH analisadas é reforçada pela predominância do endosso, um recurso para a contração dialógica. Essa estratégia de contração dialógica mostra a ausência de imparcialidade nesses textos, indicando um alto grau de engajamento do jornalista com o conteúdo do enunciado da voz do cientista (MOTTA-ROTH, LOVATO, 2011 , p. 560), conforme demonstra o exemplo 3.

Exemplo 3

$\mathrm{CH \# 3} \mathrm{Cientistas} \mathrm{brasileiros} \mathrm{confirmam} \mathrm{eficácia} \mathrm{da} \mathrm{aplicação} \mathrm{de} \mathrm{um} \mathrm{ácido} \mathrm{graxo} \mathrm{extraído} \mathrm{de} \mathrm{plantas} \mathrm{na}$ redução de tumores cerebrais em ratos.

O exemplo 3 mostra como a escolha do processo "confirmar" sugere um alinhamento do jornalista com o conteúdo projetado, ao apresentá-lo como uma verdade absoluta.

Assim como na $\mathrm{CH}$, na GL, os sentidos da expansão dialógica são construídos especialmente pelo acolhimento e pela atribuição por reconhecimento, como demonstra a Tabela 2.

Tabela 2. Mapeamento do Subsistema de Engajamento nas notícias na Galileu:

\begin{tabular}{|c|c|c|c|c|c|c|c|c|c|}
\hline \multirow{3}{*}{ Galileu } & \multicolumn{3}{|c|}{ Expansão dialógica } & \multicolumn{5}{|c|}{ Contração dialógica } & \multirow{3}{*}{ Total } \\
\hline & \multirow[t]{2}{*}{ Acolher } & \multicolumn{2}{|l|}{ Atribuir } & \multicolumn{2}{|c|}{ Refutar } & \multicolumn{3}{|l|}{ Declarar } & \\
\hline & & Reconhecer & Distanciar & Negar & Contestar & Concorrer & Pronunciar & Endossar & \\
\hline Total parcial & 20 & 30 & 06 & 06 & 09 & 03 & 01 & 11 & \multirow{4}{*}{86} \\
\hline$\%$ & $35 \%$ & $53 \%$ & $10 \%$ & $20 \%$ & $30 \%$ & $10 \%$ & $3 \%$ & $3 \%$ & \\
\hline Total absoluto & \multicolumn{3}{|l|}{56} & \multicolumn{5}{|l|}{30} & \\
\hline$\%$ & \multicolumn{3}{|l|}{$65 \%$} & \multicolumn{5}{|l|}{$34 \%$} & \\
\hline
\end{tabular}


Os exemplos 4 e 5 ilustram a ocorrência do acolhimento e da atribuição por reconhecimento (itálico) na GL.
Exemplo 4
GL\#3 Quando no organismo, parasitas eliminariam uma substância que inibiria reações alérgicas.
GL\#4 Genes 'melhores' podem fazer mulher ter mais parceiros

No exemplo 4, ilustramos a ocorrência da expansão dialógica por meio do acolhimento. Através da utilização do futuro do pretérito simples eliminariam e inibiriam (GL\#3), dando a ideia de incerteza e irrealidade, e do modal de probabilidade podem fazer (GL\#4). O emprego de verbos modais sugere que a voz autoral busca diminuir o grau de comprometimento com o conteúdo de sua própria declaração, produzindo um efeito de suposição e, desse modo, considerando a possibilidade de existirem pontos de vista alternativos. Esse efeito é causado também pelo emprego das circunstâncias de ângulo Segundo (GL\#8) e de acordo (GL\#10), conforme ilustra o exemplo 5 .

\section{Exemplo 5}

GL\#8 Segundo um estudo publicado no American Journal of Respiratory and Critical Care Medicine, uma proteína chamada GM-CSF controla o surgimento de inflamações no pulmão dos fumantes.

GL\#10 De acordo com o estudo, a FDA (Agência do governo norte americano que regulamenta alimentos e remédios) investiga se efeitos nocivos da vitamina A estão ligados ao fato dela poder ser substância fotocarcinogênica.

A ausência de imparcialidade nas notícias de PC da GL é ressaltada também pela recorrência significativa da contração dialógica pelo endosso, mostrando que o discurso nas notícias de PC se estrutura a partir da voz de atores sociais ligados à ciência (LOVATO, 2010, p. 73), representados, metonimicamente, no exemplo 6, por "Pesquisas".

\section{Exemplo 6}

GL\#2 Pesquisas mostram que insegurança e falta de qualificação para o cargo podem levar a aumento de agressividade.

Assim como na $\mathrm{CH}$ e na GL, na SCIAMB, também é predominante o acolhimento e a atribuição por reconhecimento, conforme a Tabela 3.

Tabela 3. Mapeamento do Subsistema de Engajamento nas notícias da Scientific America Brasil:

\begin{tabular}{|c|c|c|c|c|c|c|c|c|c|}
\hline \multirow{3}{*}{ SCIAMB } & \multicolumn{3}{|c|}{ Expansão dialógica } & \multicolumn{5}{|c|}{ Contração dialógica } & \multirow{3}{*}{ Total } \\
\hline & \multirow{2}{*}{ Acolher } & \multicolumn{2}{|c|}{ Atribuir } & \multicolumn{2}{|c|}{ Refutar } & \multicolumn{3}{|c|}{ Declarar } & \\
\hline & & Reconhecer & Distanciar & Negar & Contestar & Concorrer & Pronunciar & Endossar & \\
\hline Total parcial & 26 & 43 & 03 & 08 & 08 & $\mathbf{0}$ & 05 & 13 & \multirow{4}{*}{106} \\
\hline$\%$ & $36 \%$ & $60 \%$ & $4 \%$ & $22 \%$ & $22 \%$ & 0 & $16 \%$ & $37 \%$ & \\
\hline Total absolute & \multicolumn{3}{|c|}{71} & \multicolumn{5}{|c|}{35} & \\
\hline$\%$ & \multicolumn{3}{|c|}{$66 \%$} & \multicolumn{5}{|c|}{$33 \%$} & \\
\hline
\end{tabular}

O exemplo 7 ilustra a ocorrência da expansão dialógica (itálico) nas notícias da SCIAMB.

Exemplo 7

SCIAMB\#4 Coração pode revelar informações sobre a saúde dos rins.

SCIAMB\#7 Os sintomas também podem incluir aborto e infertilidade.

SCIAMB\#2 Segundo Roy-Byrne, os resultados mostraram como se poderia usar a tecnologia para tratar uma ampla gama de transtornos de ansiedade.

SCIAM\#8 Chapmam diz que as empresas podem usar os resultados do estudo como base e compará-lo com as ações realizadas em suas próprias cozinhas. 
Na SCIAMB, também não há um distanciamento explícito da voz autoral em relação às suas próprias declarações e às declarações das vozes externas inseridas nas notícias. Mantém-se um discurso velado, construído pelo emprego da atribuição por reconhecimento através da utilização da circunstância de ângulo segundo (SCIAMB\#2) e do processo verbal diz (SCIAMB\#8). O discurso é modalizado, como na $\mathrm{CH}$ e na GL, são empregados recorrentemente modais de probabilidade, tais como pode revelar (SCIAMB\#4) e podem inibir (SCIAMB\#2). O endosso também é uma estratégia de contração dialógica constante nas notícias de PC da SCIAMB, conforme demostra o exemplo 8.

Exemplo 8

SCIAMB\#3 Os autores concluem que parar de fumar durante a gravidez sem ativamente evitar a exposição ao fumo de segunda mão não protege o feto em desenvolvimento.

A escolha do verbo "concluem" induz o leitor a se solidarizar com o conteúdo do enunciado, reduzindo a possibilidade de contestação.

\subsection{Popularização da ciência: democratização do conhecimento?}

A literatura especializada em popularização da ciência tem ressaltando o questionamento sobre o caráter democrático dessa prática social (OLIVEIRA, 2007, SAN JUAN FRANÇA, 2005, VILAS BOAS, 2005, por exemplo). Esse questionamento pode ser atribuído, em grande parte, ao fato do processo de popularização da ciência se encontrar em um terreno de debates (MYERS, 2005) entre o educar, o informar e o entreter. Informar a sociedade sobre os acontecimentos públicos é uma das funções do jornalismo, mas inscrever a ciência na agenda das pessoas no geral é uma das funções da divulgação científica.

É consenso entre os jornalistas que trabalham com jornalismo científico a necessidade de informar a sociedade com responsabilidade sobre as pesquisas que estão sendo realizadas no âmbito científico e os benefícios e os riscos que essas pesquisas geram (OLIVEIRA, 2007; SAN JUAN FRANÇA, 2005; IVANISSEVICH, 2005, por exemplo). No entanto, observamos que, nas notícias de PC analisadas, não há lugar para a divergência, somente o pesquisador que realizou a pesquisa é chamado para avaliar os fenômenos científicos reportados. Embora haja a predominância dos elementos linguísticos que realizam a expansão dialógica para criar uma atmosfera imparcial e objetiva, a recorrência exclusiva da voz do cientista nesses textos anula a objetividade, construída, segundo Traquina $(2005,139)$, pela presença de diferentes opiniões sobre o fato noticiado. Há desse modo, uma midiatização da ciência sem visão crítica, sugerindo uma atitude de "subserviência em relação aos porta-vozes da ciência (OLIVEIRA, 2007, p. 48)", que vai de encontro ao caráter democrático inerente a essa prática.

Ao se divulgar um trabalho científico sem citar outras conclusões ou visões sobre o mesmo assunto, dáse a impressão ao leitor de aquele se constitui uma verdade absoluta. O papel do jornalista acaba não sendo muito diferente daquele que seria de um assessor de imprensa do pesquisador que deu a entrevista. (SAN JUAN DE FRANÇA, 2005, p. 42)

Tanto a CH, quanto a GL e a SCIAMB enfatizam os aspectos positivos e superlativos da pesquisa científica popularizada. "A cobertura da mídia sobre ciência costuma favorecer a indiferença", é um produto a ser consumido para entretenimento "nas noites de domingo em vez de tema importante na agenda social" (San Juan França, 2005, p. 43).

\section{CONSIDERAÇÕES FINAIS}

Neste trabalho, tivemos como objetivo analisar como os sentidos de objetividade e de imparcialidade são construídos discursivamente em 30 notícias de $\mathrm{PC}$ por meio da análise dos recursos linguísticos que realizam o Subsistema de Engajamento. Os resultados indicam que predomina a expansão dialógica por meio do acolhimento e da atribuição por reconhecimento. A predominância dos sentidos que constroem a expansão dialógica sugere a maximização do espaço dialógico nas notícias analisadas. Fontes externas, projetadas por circunstâncias de ângulo e processos verbais neutros, são chamadas para avaliar e explicar o tópico na notícia. O discurso é modalizado, declarações assertivas são evitadas, as informações veiculadas são apresentadas à audiência como mais ou menos prováveis, contribuindo para a construção de um efeito de objetividade e de imparcialidade no nível da léxico-gramática. No entanto, no nível discursivo, a 
objetividade e a imparcialidade são anuladas pela ausência de diferentes perspectivas sobre a descoberta científica popularizada.

A retórica nas notícias analisadas identifica, portanto, o processo de popularização da ciência como uma mera tradução e simplificação do processo científico (HILGARTNER, 1990). Há, desse modo, uma contradição em relação ao papel da popularização da ciência na sociedade. Nas notícias de PC analisadas, o jornalista assume o papel de mero informante (MOTTA-ROTH; LOVATO, 2011, p. 264). Essa prática contribui para reforçar a visão de ciência como uma prática neutra e não como "resultado de decisões politicas e econômicas, parte de uma atividade social, e, portanto, acessível a toda população (SAN JUAN FRANÇA, 2005, p. 44)”. Desse modo, a popularização da ciência perde seu papel social, com função primordial de promover condições para que os indivíduos entendam a realidade que os cerca, atuando positivamente e produtivamente nas discussões públicas sobre os benefícios que as pesquisas científicas podem ou não trazer e aplicando esse conhecimento em suas atividades cotidianas.

Os trabalhos de Marcuzzo (2011) e de Nascimento (2011) apresentam uma análise detalhada de algumas das questões desenvolvidas no artigo. Ressaltamos também que os dados apresentados nessa análise estão sendo aprofundados na pesquisa de doutorado e que uma versão mais atualizada pode ser encontrada em Motta-Roth e Lovato (2011).

\section{REFERÊNCIAS}

CABRAL, S. S.; BARROS, N. C. Linguagem e avaliação: uma análise de texto opinativo. In: INTERNATIONAL SYSTEMIC FUNCTIONAL CONGRESS, 23., São Paulo, SP. Proceedings... São Paulo, SP: LAEL-PUC-SP, 2006. p. 722-734.

CALSAMIGLIA, H.; FERRERO, C. Role and position of scientific voices: reported speech in the media. Discourse Studies, v. 5, n. 2, p. 147-173, maio 2003.

CHARAUdEAU, P. Discurso das mídias. São Paulo: Contexto, 2009.

GERMANO, M. Popularização da ciência como ação cultural libertadora. In: COLÓQUIO INTERNACIONAL PAULO FREIRE: DESAFIOS À SOCIEDADE MULTICULTURAL, 5., 2005.

; KULESZA, W. A. Popularização da ciência: uma revisão conceitual. Caderno brasileiro de ensino de Física, v. 24, n. 1, p. 7-25, abr. 2007.

HILGARTNER, S. The dominant view of popularization: conceptual problems, political uses. Social studies of science, v. 20, n. 3, p. 519-139, agos. 1990.

IVANISSEVICH, A. A mídia como interprete: como popularizar a ciência com responsabilidade e sem sensacionalismo. In: VILAS BOAS, S. (Org.). Formação \& Informação científica: jornalismo para iniciados e leigos. São Paulo: Summos editorial, 2005, p. 19-30.

LOVATO, C. dos S. Análise de Gênero: investigação da organização retórica de notícias de popularização da ciência na revista Ciência Hoje Online. 2010. 102 f. Dissertação (Mestrado em Estudos linguísticos) Universidade Federal de santa Maria, Santa Maria, 2010.

MARCUZZO. P. Ciência em debate? Análise do gênero notícia de popularização científica. 2011. 176f. Tese (Doutorado em Linguística) - Universidade Federal de Santa Maria, Santa Maria, 2011.

MARTIN, J.; WHITE, P. The language of evaluation: appraisal in English. New York: Palgrave, 2005.

MIGUEL. L. F.; BIROLI, F. A produção da imparcialidade: a construção do discurso universal a partir da perspectiva jornalística. Revista brasileira de Ciências Sociais, v. 25, n. 73, p. 59-174, jun. 2010.

MOTTA-ROTH, D. Análise crítica de gêneros com foco em artigos de popularização da ciência. Projeto de Produtividade em Pesquisa PQ/CNPq (nº. 301962/2007-3), 2007.

; LOVATO, C. dos S. Organização retórica do gênero notícia de popularização da ciência: um estudo comparativo entre português e inglês. Linguagem em (Dis)curso, v. 9, n. 2, p. 273-302, maio/ago. 2009.

; LOVATO, C. dos S. O poder hegemônico da ciência no discurso de popularização científica.

Calidoscópio, v. 9, n. 3, p. 251-268, set./dez. 2011 
MYERS, G. Discourse studies of scientific popularization: questioning the boundaries. Discourse studies, v. 5, n. 1, p. 265-279, maio 2003.

NASCIMENTO, F. 'GM crops may be harmful to the environment': graus de autoridade e assertividade em notícias de popularização da ciência. 2011. 114f. Dissertação (Mestrado em Estudos Linguísticos) Universidade Federal de Santa Maria, Santa Maria, 2011.

OLIVEIRA, F. Jornalismo científico. São Paulo: Contexto, 2007.

SAN JUAN FRANÇA, M. Divulgação ou jornalismo? Duas formas diferentes de abordar o mesmo assunto. In: VILAS BOAS, S. (Org.). Formação E̊ informação científica: jornalismo para iniciados e leigos. São Paulo: Summos editorial, 2005, p. 31-47.

VILAS BOAS. S. Ciência e ciências: In: VILAS BOAS. S. (Org.) Formação E̊ informação: jornalismo para iniciados e leigos. São Paulo: Summos Editorial, 2005, p. 07-13.

Recebido em 17/04/11. Aprovado em 13/o2/12. 